\title{
Editorial
}

\section{Sobre o perfil dos manuscritos que aqui temos buscado} About the profile of manuscripts that we have sought here

A produção incessante do conhecimento chama um movimento que transcenda os limites disciplinares e se aventure em outros campos do saber. A complexidade e profundidade do que já se produziu em cada área especificamente impossibilita que ainda acreditemos que o conhecimento acerca de um objeto se esgote em uma área apenas.

É por meio deste princípio e proposta que a Revista de Ciências Humanas da Universidade Federal de Santa Catarina se caracteriza. Nós, do Centro de Filosofia e Ciências Humanas, entendemos que o conhecimento se constrói de forma aberta e inacabada, no contexto de uma teia onde as linhas se entrelaçam formando redes de saberes. Daí a importância da produção deste periódico na perspectiva que lhe caracteriza: ser uma objetivação de parte das pesquisas e investigações que compõem cada linha desta trama.

Sob este horizonte, abrimos o número dois do volume quarenta e sete com o artigo intitulado $\square$ Discurso e as Transformações Sociais $\square$, de autoria de José Rosamilton de Lima e Ivanaldo Oliveira Santos. Trata-se de um trabalho que aborda as diferentes fases da Análise do Discurso, enfocando sua importância para estudos sobre o discurso como social e coletivo, contextualizado historicamente e capaz de transformações sociais.

Rafael de Oliveira Rodrigues e Soraia G. F. de P. Cruz, no artigo Interlocuções entre Psicologia e Direitos Humanos: práticas interventoras $\square$, relatam uma pesquisa-intervenção junto a adolescentes, discutindo sobre direitos humanos e cidadania, visando produzir um conhecimento que vise afirmar espaços e intensificar alteridades. Discutindo desigualdades sociais, o artigo "Os Relatórios do Desenvolvimento Humano e os seus Diálogos com Alguns Estudos sobre Desigualdades $\square$, de autoria de $\mathrm{M}^{\mathrm{a}}$ José de Rezende, aponta os Relatórios do Desenvolvimento Humano, colocando-os como passíveis de serem indicativos de mudanças que visem a expansão do desenvolvimento humano.

O artigo $\square$ A Interface da Psicologia com a Saúde Mental: o uso de oficinas estéticas em um hospital psiquiátrico $\square$, de Marcela A. Gomes e Camila O. da Silva, trata do sofrimento psíquico na complexidade dos processos saúde/ 
doença e subjetivação/singularização do sujeito, trazendo as oficinas estéticas como ferramentas de mobilização para o enfrentamento desse sofrimento, compreendido como sendo também ético-político. Ainda em torno das questões da saúde, o artigo O Processo de Ensino e Aprendizagem em Educação em Saúde no Município Brasileiro de Lages $\square$, de autoria de Anderson C. de Oliveira, Bruna P. Dondé, Ana Paula Veloso, Priscila G. da Silva e Rodrigo D. de Vivar Y Soler, indagam como ocorre a relação entre a comunidade e os profissionais, objetivando compreeender como acontece o processo de ensino e aprendizagem em uma Unidade Básica de Saúde.

"Compreensões da Educação Ambiental: possibilidades e desafios do paradigma da complexidade $\square$ é o artigo de autoria de Filipi V. Amorim e Humberto Calloni que versa sobre a importância da ideia de complexidade para se pensar a Educação Ambiental e a crise em torno do meio ambiente, apontando para um paradigma integrador dos diferentes saberes.

José Henrique Rollo Gonçalves, no artigo $\square$ Mobilidade Social na Idade Média: um breve estudo sobre os ministeriales na Alemanha $\square$, apresenta algumas características de um grupo social que experimentou a mobilidade social vertical, como um grupo importante dos séculos IX a XIII. Da Sindicalização às Ocupações: luta pela terra em Minas Gerais (1940-1980) $\square$ é o artigo de autoria de Arnaldo J. Zangelmi, Fabrício R. C. Oliveira e Izabella F. O. de Sales, o qual reflete sobre parte do processo de luta pela terra em Minas Gerais que, por meio da História Oral e da Micro-história, analisam algumas das suas principais mobilizações, atores e desdobramentos. No artigo Celebrações e Linguagem na Imagem do Asilo de Infância Desvalida da Horta, Portugal, 1858-1910 , Sandro Serpa discute o papel das celebrações e da linguagem utilizada na organização, concluindo que podem desempenhar um papel relevante no fomento da sua imagem positiva externa, fazendo-se fundamental para a sua sobrevivência e continuidade.

Finalizando a exposição de artigos, Beatriz Schmidt, Edite Krawulski e Renatto C. Marcondes, no artigo $\square$ Psicologia e Gestão de Pessoas em Organizações de Trabalho: investigando a perspectiva estratégica de atuação $\square$ discutem a prática do psicólogo organizacional. Os autores partem da produção científica nacional, identificando que há escassez de produções sobre a atuação estratégica em gestão de pessoas e marcam que esta atividade ainda representa um desafio a este profissional.

Em seguida, apresentamos o trabalho de Fabienne Hulak, intitulado Linvention d un Dispositif comme Suppléance au Défaut de la Métaphore Paternelle : effectuer la torsion de 1 unilatère $\square$, traduzido como $\square$ A Invenção 
de um Dispositivo como Suplência à Metáfora Paterna: efetuar a torção da superfície unilateral $\square$

Por fim, apresentamos a Resenha, escrita por José Maurício de Carvalho, da obra $\square$ Pessoa e Dignidade Humana $\square$, de Urbano Zilles, publicada pela Editora CRV.

Com a perspectiva de que as múltiplas temáticas clamam por conhecimentos que se constituem necessariamente entrelaçados, é que entendemos ser necessário apostar cada vez mais em uma consolidação deste entrelaçamento, incentivando a produção e a divulgação do conhecimento também nesta perspectiva.

Se você entende que sua produção se caracteriza por esta ótica, convidamos você a publicar conosco e a fortalecer o olhar interdisciplinar em Ciências Humanas.

Agora, com o segundo número do Volume 47, desejamos a você uma excelente leitura!

Kátia Maheirie

Editora Geral 